\title{
Effect of the Methyl Group on the Stability and Twisting of Flavonoids
}

\author{
Milene A. R. de Oliveira, Keylla U. Bicalho \& João B. Fernandes
}

\section{Introduction}

Flavonoids is a class of phytochemicals/phytonutrients originated from polyphenols of low molecular weight found in several plants ${ }^{1}$. They present good effects on human health such as active role on sickness healing. These compounds are classified as the most important natural colorants and flavors besides presenting a wide range of biological activities, highlighting the anti-inflammatory ${ }^{2}$ and antioxidant 3 properties. They are found in hydro and liposoluble forms, and as aglycones (without sugar units) or glycosides flavonoids ${ }^{4,5,6}$.

Some great sources of flavonoids are the seeds and fruits of plants from the Leguminosae and Compositae families ${ }^{7}$. More than 5000 flavonoids have been identified in the nature and classified according to their chemical structure. This class of compounds is subdivided in 9 subgroups: flavones, flavonols, flavanones, flavanes, isoflavones, anthocyanins, flavanonols (flavan-3-ol or cathechins), chalcones and dihydrochalcones

The computational chemistry is a powerful tool that can help better understanding some of the doubts questioned in this work. With the advance of the computational chemistry, is even more needed and easy to explain some experimental observations based on the quantic chemistry ${ }^{8}$ from many studies found on literature ${ }^{9,10,11-14}$. This kid of study provides valuable information at low costs, that allows to understand the effect of the different structural features of the compounds. Some theoretical studies about a great variety of flavonoids were published ${ }^{12}$, where some of them focus on the energetic properties of these compounds and the effect of the hydroxyl groups on the structure.

In this perspective, this work presents the results from a study of four glycoside flavones. Figure 1 shows the representation of the general structure for flavonoids, including the ones discussed in this research. This molecular structure is characterized by charge delocalization on the studied molecules from ring $\mathrm{A}$ to $\mathrm{B}$ trough $\mathrm{C}$ due to the double bond $\mathrm{C} 2-\mathrm{C} 3$. Then, the main question of this work is to understand how the presence of the methyl group affects the charge delocalization and how it is related to the geometrical and molecular parameters and the molecular energy, as well as the twisting profiles around the C2-C1' bond and its effect on rotation properties of cathecol (ring B). The intramolecular hydrogen bonds will also be studied. Density Functional Theory (DFT) was applied in this work since it provides confident results between the precision and computational requirements, considering the compounds studied and its properties.

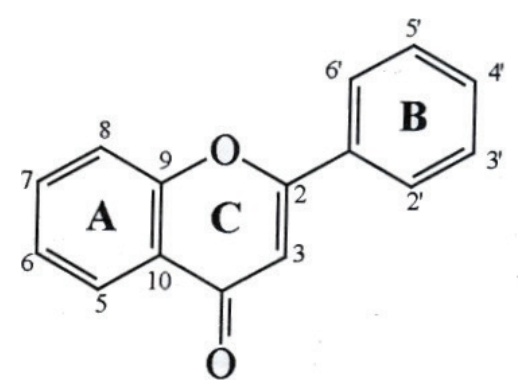

Figura 1. Molecula skeleton of flavone showing atoms numeration and named rings. 
The flavones have the same basic structure derived from the original molecule presented in Figure 1 and the optimized structures for the compounds I-IV studied in this work are presented in Figure 2. In these compounds, the methyl, glucosyl and hydroxyl groups are alternating in the positions 3 and 7 .

\section{Computational Methods}

DFT calculations were performed with the Gaussian 0515 pack according to the Density Functional Theory, using the exchange of corrected functional gradient of Becke16 and Lee-Tang-Parr functional correlations17. For these parameters, the B3LYP method was used18. The set of bases $6-311++\mathrm{G} * *$ was used for the calculations presented in this work. The atomic charges, bonds length and dihedral angles were calculated for the optimized structures in gas phase and in vacuum.

\section{Results and Discussion}

\section{STRUCTURAL FEATURES}

The optimizations of the four structures presented in Figure 2 were performed and the intramolecular hydrogen bonds in the structures and the main molecular parameters are showed in Table 1.

As discussed in Santiago Aparício work20, the dihedral angle between ring $\mathrm{B}$ and the plane formed by rings $\mathrm{A}$ and $\mathrm{C}$ is about $20^{\circ}$ for flavones without the hydroxyl group and $0^{\circ}$ for the ones with hydroxyl group at position 3. In our results is observed that both structures with the methyl group presented a dihedral angle, between the plane of the rings $\mathrm{A}-\mathrm{C}$ and $\mathrm{B}$ (C3-C2$\mathrm{C} 1^{\prime}-\mathrm{C} 2^{\prime}$ ) of $-71,36^{\circ}$ (Structure I) e $0,49^{\circ}$ (Structure II), and the structures with the hydroxyl, $-23,18^{\circ}$ (Structure III) and $-0,05^{\circ}$ (Structure IV).

The values obtained indicate that the glucosyl group present on structures at position 3, confirms the significant change in the dihedral angle. This observation can also be explained by the intramolecular hydrogen bonds present in these molecules. On structure I, the hydrogen bond between the hydroxyl hydrogen 7 at the glucosyl group with the oxygen at position 2' from ring $\mathrm{B}$, can justify the noncoplanarity between these rings, once this bond is 1.85341 $\AA$, which is considered as strong bond 21 . On structure II the rings are almost coplanar and that is explained by the hydrogen bond between the oxygen bonded to methyl at position 3 and the hydrogen at position 2' from $\mathrm{B}$ ring, where the distance is $2.29746 \AA$

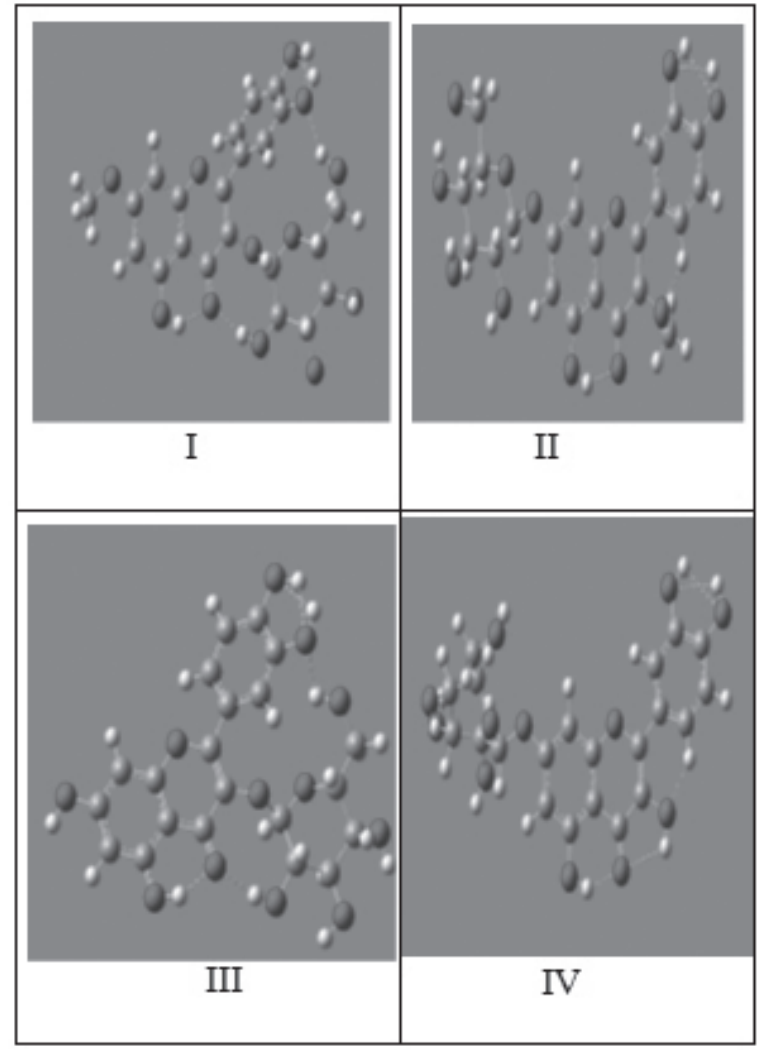

Figure 2 - Optimized structures of the studied flavones I-IV from the calculation in gas phase on B3LYP//6-311 ++ G** theoretical level, with indication of the hydrogen bonds. Atom Colour code: Oxigen (red), carbon (grey) and hydrogen (white).

For structures III and IV, that have the hydroxyl changing by glucosyl, follows the same tendency of III that has the sugar unit at position 3, the B ring has a small rotation due to the hydrogen bond between the hydroxyl hydrogen 7 at glucosyl unit with the oxygen at position 2' at B (1.91915 $\AA$ ), and for structure IV, the rings can be considered coplanar, where the intramlecular bond between the hydrogen at position 2' and the oxygen at position 3 is considered strong (1.79635 $\AA$ ). Table 2 shows 
the intramolecular hydrogen bonds on these structures.

In terms of stability, is observed that when the glucosyl in the molecule is at position 3 , it is more stable than its correspondent at position 7. Since the atom of $\mathrm{C}, \mathrm{O}$ and $\mathrm{H}$ has a contribution of -38.2792077 a.u, -74.46309364 a.u and -0.56119365 a.u, respectively, for the stabilization energy of a molecule (not considering the contributions from hydrogen bonds, radicals and ions), it is possible to compare the stabilization of the four structures (I-IV).

Atom numeration as Figure 1. Interatomic distances, $\mathrm{r}$ in $\AA$; dihedral angles, $\tau$, in degrees; energy E in a.u.; dipole moment, $\mu$, in D.

Table 1. Main geometrical and energetic parameters from the studied flavones I-IV in gas phase calculated in the B3LYP / 6-311 ++ $\mathrm{G}^{* *}$ theoretical level.

\begin{tabular}{|c|c|c|c|c|c|}
\hline Structure & $\begin{array}{c}\mathbf{r} \\
\mathbf{C 4 =} \mathbf{O}\end{array}$ & $\begin{array}{c}\mathbf{r} \\
\mathbf{3 - O H}\end{array}$ & $\begin{array}{c}\mathbf{r} \\
\mathbf{5 - O H}\end{array}$ & $\begin{array}{c}\mathbf{r} \mathbf{3}^{\prime}- \\
\mathbf{O H}\end{array}$ & $\begin{array}{c}\mathbf{r} \mathbf{4} \text { '- } \\
\mathbf{O H}\end{array}$ \\
\hline I & 1.235 & -- & 0.975 & 0.961 & 0.959 \\
\hline II & 1.230 & -- & 0.965 & 0.961 & 0.941 \\
\hline III & 1.263 & -- & 0.994 & 0.966 & 0.969 \\
\hline IV & 1.234 & 0.951 & 0.985 & 0.963 & 0.968 \\
\hline
\end{tabular}

Table 2 - Intramolecular hydrogen bonds in $\AA$.

\begin{tabular}{|c|c|c|c|c|}
\hline Structures & C2'H-O3 $^{\prime}$ & O3'H-O4' $^{\prime}$ & O4'H-O3' $^{\prime}$ & O5H-O4 $^{\prime}$ \\
\hline I & 3.30500 & 2.50884 & 2.50348 & 1.81243 \\
\hline II & 1.80116 & 2.49596 & 2.49636 & 1.81245 \\
\hline III & 3.17287 & 2.15164 & 2.18359 & 1.691006 \\
\hline IV & 1.79594 & 2.49790 & 2.49531 & 1.82113 \\
\hline
\end{tabular}

Table 3 - Huckel charge calculated by the B3LYP method with base 6-311 + $\mathrm{G} * *$ for I-IV

\begin{tabular}{|c|c|c|c|c|c|}
\hline Structures & C4= O & C3-O & C5-O & C7-O & C4'-O \\
\hline I & 0.602 & 0.556 & 0.554 & 0.516 & 0.547 \\
\hline II & 0.571 & 0.544 & 0.558 & 0.527 & 0.549 \\
\hline III & 0.609 & 0.550 & 0.557 & 0.542 & 0.568 \\
\hline IV & 0.594 & 0.544 & 0.559 & 0.531 & 0.550 \\
\hline
\end{tabular}

Therefore, removing one $\mathrm{CH} 2$ group from the structures I and II, it is obtained an energy of -1714.90063333 a.u and -1714.8854695 a.u, respectively. The comparison of the four calculated energies for I-IV, we can conclude that having a hydroxyl group (structure III) instead of a methyl group results in a more stable molecule, which agrees with the lower dipole moment for this structure. The Table 3 shows the Hückel charges, and it can be observed that the most electronegative atom is the carbonyl oxygen and that on the structure III the charge is bigger. The crescent order for these oxygens from the structures would be III $>$ I $>$ IV $>$ II. This crescent order for the Hückell charge on the carbonyl oxygen is equivalent to the crescent order of the stability of the studied structures, confirming that the structures with the glucosyl at position 3 is more stable than when it is at position 7, regardless if they have hydroxyl or an methyl group at position 7 .

\section{Conclusions}

It can be concluded from this work that the methyl group decreases the stability on the studied structures, either if they are at 3 or 7 position, but the structures with the glucosyl at position 3 are more stable than when the glucosyl is at position 7, no matter if it has a hydroxyl or a methyl group. It can also be concluded that the methyl group does not influence on the ring B twisting, once it is connected with an oxygen that has an intramolecular bond with the hydrogen at position 1' at ring B. On the other hand, when the flavone has the glucosyl unit at position 3 , the tendency is that the planarity of ring $\mathrm{B}$ in relation to the ring A-C does not occurs. The Hückel charge has a linear relationship with the stability of the studied structures.

\section{Acknowledgments}

The authors are grateful for the support given from the FAPEG, CAPES, CNPQ and FINATEC.

\section{References}

1. SIMÕES, C. M. O. (organizadora). Farmacognosia: da planta ao medicamento. Porto Alegre/Florianópolis: Ed. Universidade / UFRGS/Ed. da UFSC (2000).

2. PATHAK, D.; PATHAK, K.; SINGLA, A.K. Flavonoids as 
medicinal agents: recent advances. Fitoterapia, 57, 371(1991).

3. RICE-EVANS, C.A.; MILLER, N.J.; BOLWELL, G.P.; BRAMLEY, P.M.; PRIDHAM, J.B. The relative antioxidant activities of plant derived polyphenolic flavonoids. Free Radical Res. 22, 375 (1995).

4. TREASE, G.E.; EVANS, W.C. Phenols and phenolic glycosides. In: Pharmacognosy 14.ed. London: W.B. Saunders, 218 (1996)

5. YAO, L.H.; JIANG, Y.M.; SHI, J.; TOMÁS-BARBERÁN, F.A.; DATTA, N.; SINGANUSONG, R.; CHEN, S.S. Flavonoids in food and their health benefits. Plant Foods Hum. Nutr. 59, 113(2004)

6. Acker, S.A.B.E.V.; Berg, D.J.V.B.; Tromp, M.N.J.L.; Griffioen, Bennekom, W.P.V.; Vijgh, W.J.F.V.D.; Bast, A. Structural aspects of antioxidant activity of flavonoids. Free Radical Biol. Med. 20, 331(1996).

7. Cramer, C. J.; Essentials of Computational Chemistry: Theories and Models, 2a ed., Wiley: Chichester, (2004).

8. van Acker, S.A.B.; de Groot, M.J.; van der Berg, D.J.; Tromp, M.N.; Donne, G.; Wim, F.J.; van der Vijgh, W.J.F.; Bast, A. A quantum chemical explanation of the antioxidant activity of flavonoids. Chem. Res. Toxicol. 9, 1305(1996).

9. van Acker, S.A.B.; de Groot, M.J.; van der Berg, D.J.; Tromp, M.N.; Griffen, D.H.; van Bennekom, W.P.; van der Vijgh, W.J.F.; Bast, A. Structural aspects of antioxidant activity of flavonoids. Free Radical Biol. Med. 20, 331(1996).

10. Antonczak, S. Electronic description of four flavonoids revisited by DFT method. J. Mol. Struc. Theochem. 856, 38(2008).

11. Lameira, J.; Alves, C.N.; Moliner, V.; Silla, E. A density functional study of flavonoid compounds with anti-HIV activity. Eur. J. Med. Chem. 41, 616(2006).

12. Leopoldini, M.; Marino, T.; Russo, N.; Toscano, M. Density functional computations of the energetic and spectroscopic parameters of quercetin and its radicals in the gas phase and in solvent. Theor. Chem. Acc. 111, 210(2004).

13. Mendoza, A.M.; Glossman, D. CHIH-DFT determination of the molecular structure; infrared and ultraviolet spectra of the flavonoid querdetin. J. Mol. Struc.-Theochem., 681, 71 (2004).

14. Olejniczak, S.; Potrzebowski, M.J. Solid state NMR studies and density functional theory (DFT) calculations of conformers of quercetin. Org. Biomol. Chem., 2, 2315(2004).

15. Frisch, M.J.; Trucks, G.W.; Schlegel, H.B.; Scuseria, G.E.; Robb, M.A.; Cheeseman, J.R.; Montgomery, J.A., Jr.; Vreven, T.; Kudin, K.N.; et al. Gaussian 03 (Revision C.02); Gaussian Inc.: Wallingford, CT, USA, (2004).

16. Becke, A.D. Density-functional exchange-energy approximation with correct asymptotic behavior. Phys. Rev. A, 38, 3098(1988).

17. Lee, C.; Yang, W.; Parr, R.G. Development of the Colle-Salvetti correlation-energy formula into a functional of the electron density. Phys. Rev. B, 37, 785(1988).
18. Becke, A.D. Density-functional thermochemistry. III. The role of exact exchange. J. Chem. Phys., 98, 5648(1993).

19. Besler, B.H.; Merz, K.M.; Kollman, P.A. Atomic charges derived from semiempirical methods. J.Comput. Chem., 11, 431-439 (1990).

20. Aparicio, S.; A Systematic Computational Study on Flavonoids. Int. J. Mol. Sci., 11, 2017(2010).

21. Rodrigues, J.A.R.; Ligações Hidrogênio fortes em ácidos dicarboxílicos e diaminas aromáticas. Quím. Nova 23, 812, (2000).

\section{Milene A. R. de Oliveira*, Keylla U. Bicalho \& João B. Fernandes}

Departamento de Química. Universidade Federal de São Carlos. São Carolos, SP

*E-mal: mileneoli1@hotmail.com 